\title{
Estudio comparativo de efectividad de un apósito de plata nanocristalina frente a sulfiadiazina argéntica en el tratamiento de pacientes quemados
}

\section{Comparative study on the effectiveness of a dressing of nanocrystalline silver opposite to the use of silver sulfiadiazine in burned patients treatment}

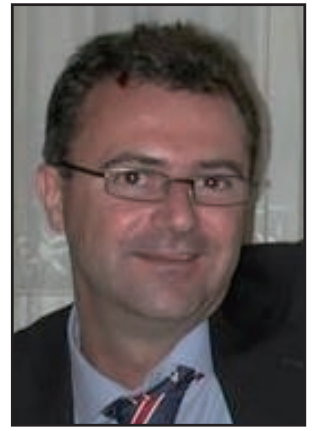

Salvador Sanz, J.F.

Salvador Sanz, J.F.*, Novo Torres, A.**, Lorda Barraguer, E.***, Castillo, F.***,

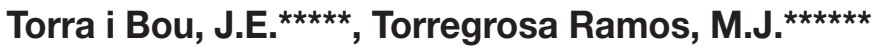

\section{Resumen}

La plata es un producto utilizado como agente antimicrobiano desde la antigüedad y ya a finales del siglo XIX se empezaron a utilizar compuestos de plata con finalidades médicas. La utilización tópica de la crema de sulfadiazina argéntica al $1 \%$ se considera mayoritariamente como tratamiento de elección para las quemaduras a fin de tratar o prevenir la infección local.

El objetivo de este artículo es comparar el tratamiento con Acticoat ${ }^{\circledR}$ (plata nanocristalina 15 nanómetros) frente al tratamiento con sulfadiazina argéntica, ambos regímenes en igualdad de condiciones y un mismo centro de quemados. También se realiza una revisión de la literatura reciente sobre los factores de riesgo para la infección en quemaduras, las medidas que se utilizan para prevenirla y su importancia en la disminución de la morbi-mortalidad.
Silver is a product that has been used as antimicrobial agent from ancient times; at the end of the XIXth century silver compounds were used with medical purposes. The use of silver sulfadiazine to $1 \%$ cream is considered as gold standard for local treatment of burns in order to prevent or to treat local infection

We compare treatment with Acticoat $\AA$ (nanocrystalline silver 15 nanometers) and silver sulfadiazine, both sistems on equal terms and in the same medical burned center. We review recent literature of risk factors for burn infection, methods to prevent it and to dininish morbimortality in burned patients.
Palabras clave Quemaduras, Tratamiento local quemaduras, Plata nanocristalina, Sulfadizacina argéntica.

Código numérico 103-154-1545
Key words Burns, Local burns treatment,

Nanocristaline Silver, Silver Sulfadiazcine.

Numeral Code 103-154-1545

\footnotetext{
* Especialista en Cirugía Plástica Reparadora y Estética. Profesor de Anatomía, Universidad Miguel Hernández. Alicante. España.

** Especialista en Cirugía Plástica Reparadora y Estética.

*** Jefe de Servicio de Cirugía Plástica y Unidad de Quemados.

**** Residente de Cirugía Plástica Reparadora y Estética.

***** Diplomado Universitario en Enfermería. Clinical Manager Smith-Nephew. Barcelona. España.

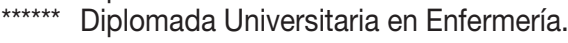




\section{Introducción}

Las infecciones constituyen actualmente la principal amenaza vital para los pacientes que superan la fase inicial de shock-resucitación tras una agresión térmica severa. Aunque clásicamente la herida cutánea ha sido el primer foco de sepsis, su importancia ha disminuido notablemente debido a los significativos avances en el manejo tópico de la quemadura, emergiendo la infección de origen pulmonar como foco séptico mas relevante y pasando las complicaciones infecciosas a ser la causa de muerte más frecuente en el paciente quemado (1).

La incidencia de complicaciones infecciosas en los pacientes quemados se incrementa en relación directa con la superficie corporal quemada, con el grado de profundidad de la quemadura y con la edad del individuo. Igualmente la mortalidad asociada a las quemaduras se correlaciona íntimamente con estos tres determinantes $(2,3)$ (Gráfica 1).

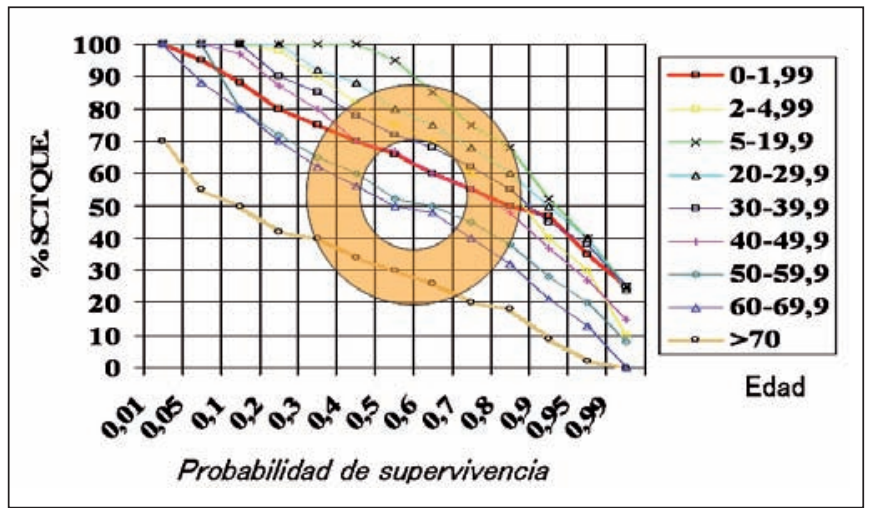

Grafica 1: Probabilidad de supervivencia correlación de SCQ y edad: en eje inferior 1 es una muy baja probabilidad de mortalidad y 0,01 es una alta posibilidad de muerte. El círculo ubica nuestra población con intervalo de confianza $\pm 10-20 \%$ SCQ. Adaptado de los datos de supervivencia 6.417 Pacientes en Unidades EEUU (3).

$S C Q=$ Superficie corporal quemada.

La quemadura produce un importante cambio en la flora dérmica del paciente, de manera que se pierde inicialmente la flora normal de piel y mucosas y se abre paso a la colonización por gérmenes más virulentos $(1,4)$. La producción de exudados ricos en proteínas y los tejidos coagulados presentes en el lecho de la quemadura constituyen un medio de cultivo ideal para los microorganismos.

El ingreso en unidades de quemados con habitaciones individúales y el régimen de aislamiento del paciente quemado son medidas eficaces en la prevención de las infecciones en este tipo de pacientes. El aislamiento es útil no solamente en lo que respecta a la disminución de las infecciones, sobre todo por gérmenes Gram negativos, sino también en el retraso en su aparición.

El uso correcto de la antibioticoterapia en estos pacientes, gravemente inmunodeprimidos, es esencial. Ningún antibiótico puede eliminar todos los potenciales patógenos y el uso injustificado de antibioticoterapia de amplio espectro solo consigue seleccionar gérmenes multirresistentes y hongos. No existe una pauta antibiótica universalmente eficaz; la elección dependerá de la situación clínica, flora y patrones de sensibilidad prevalentes en la Unidad de Quemados en cada momento, así como de los gérmenes aislados previamente en el paciente. Los cultivos rutinarios de la herida y vía respiratoria son esenciales, ya que permiten conocer la flora que coloniza al enfermo y orientan la antibioticoterapia empírica precoz y efectiva cuando aparece la infección (4-6) (Gráfica 2).

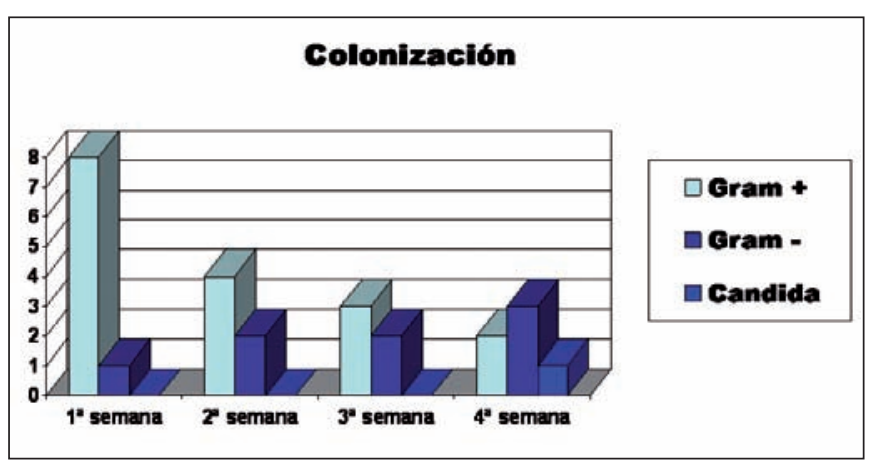

Grafica 2: Cambios de la flora bacteriana residente en la escara y su cambio en las primeras semanas, obtenidos en nuestra Unidad con cultivos cuantitativos a partir de $1 \mathrm{gr}$ de tejido en 50 pacientes.

La antibioticoterapia profiláctica sistémica postquemadura está contraindicada, pues aumenta el riesgo de infecciones graves más precoces y por microorganismos resistentes (5). En nuestra experiencia, solo está indicada la profilaxis antibiótica preoperatoria en dos situaciones: tras escarectomías y tras la realización de cierto tipo de injertos. La administración de antibioticoterapia tras escarectomías se basa en el hecho de que en el momento del desbridamiento quirúrgico se producen frecuentemente bacteriemias por la movilización de los tejidos, por lo que es útil la realización de profilaxis antibiótica prequirúrgica corta a fin de evitar resistencias y a dosis adecuadas para que en el momento de la escarectomía ya haya niveles en sangre del antibiótico. También está indicada la profilaxis antibiótica tras la realización de autoinjertos que precisan vendaje oclusivo los primeros días y con un alto riesgo de infección, especialmente por gérmenes Gram positivos (4,5) (Gráficas 3 y 4).

En el caso de desarrollo de sepsis de origen cutáneo, es necesario comenzar un tratamiento que cubra los gérmenes que con mayor frecuencia la generan. También es imprescindible el desbridamiento quirúrgico, ya que reduce la carga bacteriana de la escara. La terapia antibiótica empírica para sepsis de origen cutáneo debe ser precoz y modificarse posteriormente en función de los gérmenes aislados e identificados (4-7) (Gráfica 2).

\section{Tratamiento tópico de la quemadura}

La plata se ha utilizado como agente antimicrobiano desde la antigüedad. A finales del siglo XIX se empeza- 


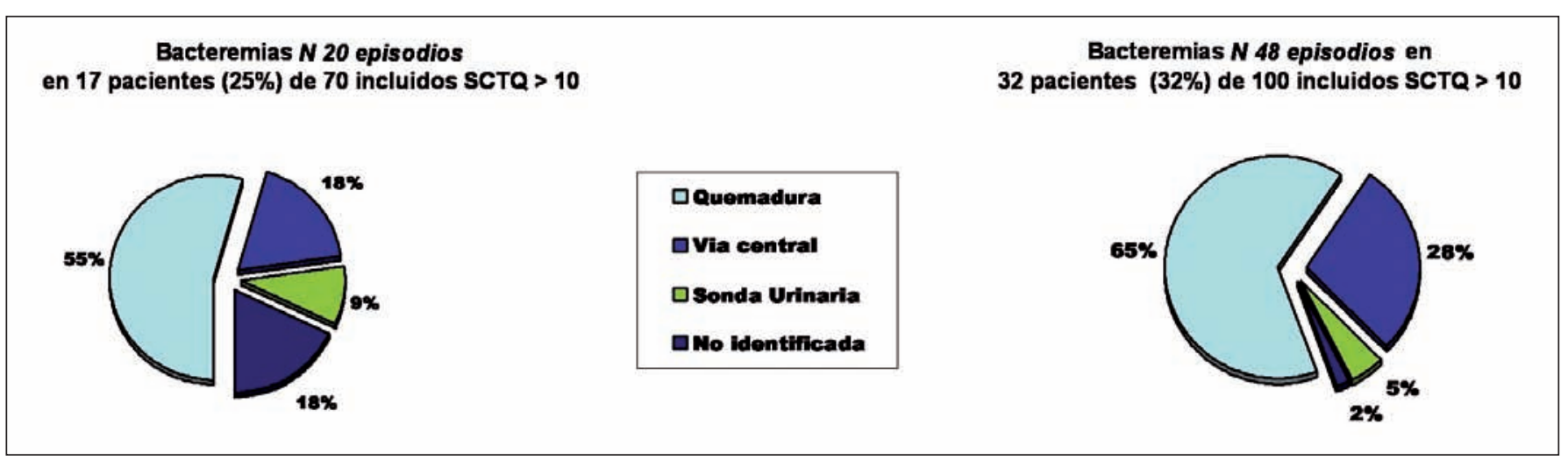

Grafica 3: Incidencia de bacteriemia con profilaxis Bacteriemias N 20 episodios en 17 pacientes (25\%) de 70 incluidos SCQ $>10$. Incidencia de bacteriemia sin profilaxis Bacteriemias N 48 episodios en 32 pacientes (32\%) de 100 incluidos SCQ $>10$ Disminuye la incidencia total de bacteriemias como el porcentaje de las bacteriemias de origen cutáneo.

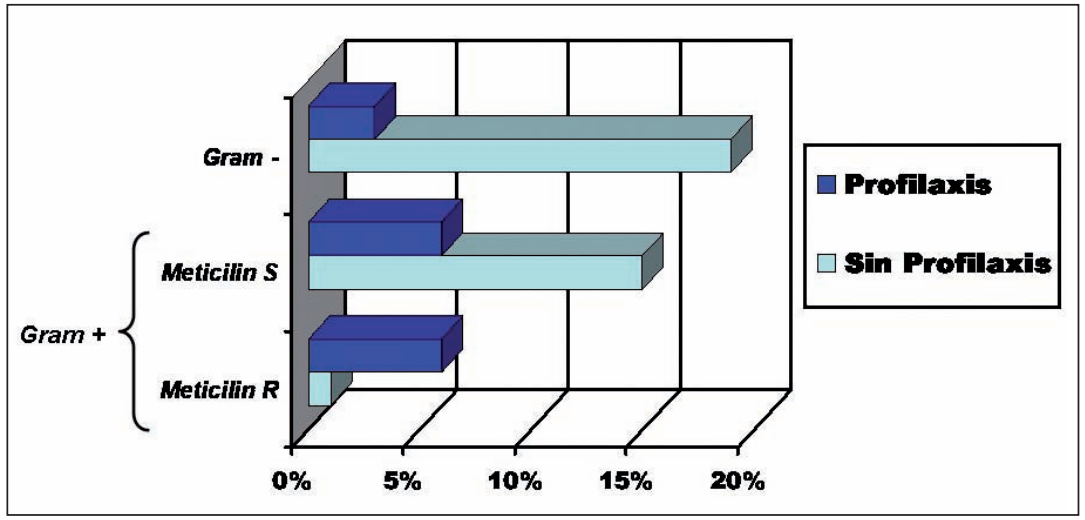

Grafica 4: Incidencia de bacteriemia agrupados en gram negativos y gram positivos con y sin profilaxis, aunque aumenta el porcentaje de bacteriemias por gram negativos y numero total de bacteriemas disminuye.

ron a utilizar compuestos de plata con finalidades médicas; el uso más destacado se dió en 1884 cuando Crede usó el nitrato de plata al $1 \%$ en solución tópica en neonatos para prevenir infecciones oculares y a principios de los años sesenta del siglo pasado, la FDA norteamericana autorizó la utilización de soluciones de nitrato de plata al $0,5 \%$ para el tratamiento local de las quemaduras. En el año 1968, Fox introdujo la utilización de la crema de sulfadiazina argéntica al $1 \%$, producto que desde hace muchos años es el de mayor uso en el tratamiento tópico de las quemaduras para tratar o prevenir la infección local. Actualmente sigue siendo considerado de forma mayoritaria como tratamiento de elección o patrón de referencia para el tratamiento local de las quemaduras (8).

La plata es considerada un agente bactericida de alta efectividad para el tratamiento general de las heridas (9). De acuerdo con la literatura, el efecto antibacteriano de la plata se debe a cuatro motivos $(8,10-12)$ :

- Porque en su forma iónica interfiere el transporte bacteriano de electrones inhibiendo la cadena respiratoria por la vía citocromos.

- Porque se fija al ADN de las bacterias y de sus esporas incrementando la estabilidad de la doble hélice, bloqueando e inhibiendo la replicación celular

- Porque interacciona con la membrana celular provocando problemas estructurales y dañando su funcionalismo.
- Porque forma compuestos insolubles y por tanto, metabólicamente inefectivos o inactivos, con enzimas, aniones y otros elementos, lo que dificulta la supervivencia bacteriana.

La amplia utilización del nitrato de plata y de la sulfadiazina argéntica en pacientes con quemaduras ha permitido demostrar la efectividad de los productos a base de plata en pacientes con éste tipo de lesiones, así como con heridas de gran complejidad y extensión en las que la infección local es un riesgo importante, a la vez que ha permitido evidenciar también algunas de sus limitaciones. Así, la crema de nitrato de plata al $0,5 \%$ no presenta efecto antibacteriano residual, por lo que requiere curas cada 2 horas y la sulfadiazina argéntica al $1 \%$ requiere curas cada 12 horas para poder mantener su efecto residual en la herida. Por otra parte, la sulfadiazina argéntica presenta como problema añadido la posibilidad de alergias y sensibilizaciones frente a la fracción sulfonamida, así como la formación de seudocostras al interactuar con el exudado, que han de retirarse antes de nuevas aplicaciones de producto.

Acticoat ${ }^{\circledR}$ (Smith\&Nephew) es un apósito barrera antimicrobiana formado por una capa central de rayónpolyester recubierta por dos capas de polietileno impregnadas de plata nanocristalina mediante un proceso especial de deposición física de plata metálica a base de vapor con gas argón. Este proceso provoca cambios en las propiedades físicas de los cristales, obteniéndose una forma de plata elemental metaestable y muy energética; permite además obtener cristales de plata nanocristalina muy pequeños y aspecto granuloso, 15 nanómetros frente a los 250 de los cristales tradicionales, lo que facilita una mayor superficie de contacto con el lecho lesional (Fig. 1). Por otra parte, la plata nanocristalina es altamente soluble, llegando a disoluciones de hasta $70 \mathrm{ppm}$. Acticoat ${ }^{\circledR}$ libera en la herida iones de plata $(\mathrm{Ag}+)$ y radicales de plata (Ag0). Los radicales de plata hacen que la plata nanocristalina sea mucho más reactiva (reacciona más rápida- 


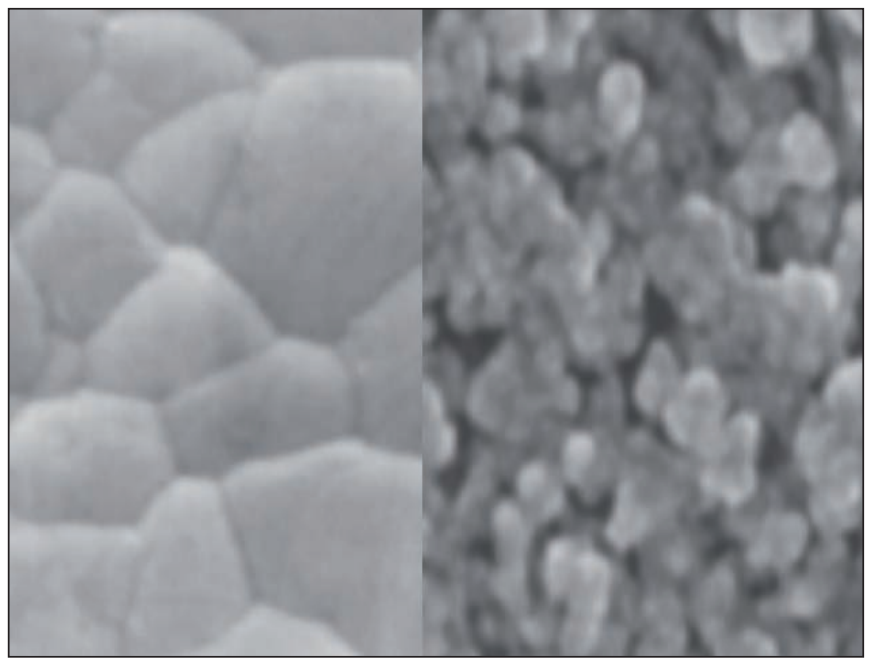

Fig. 1: Imagen de micrografía: cristales tradicionales de 250 manómetros de diámetro frente a plata nanocristalina de un tamaño muy pequeño y aspecto granuloso, 15 manómetros. Al disminuir el tamaño de las moléculas hay un aumento de la superficie de contacto con la herida y por tanto, más liberación efectiva de plata en forma iónica.

mente con las bacterias) y que se desactive menos que los $\mathrm{Ag}+$ en contacto con cloruros o materia orgánica, elementos comunes en las heridas crónicas.

Acticoat ${ }^{\circledR}$ presenta eficacia antimicrobiana ante más de 150 gérmenes, incluidos multiresistentes como Staphylococcus aureus resistente a la meticilina (SARM), Enterococcus resistente a la vancomicina (ERV) y Pseudomonas aureginosa. Es efectivo matando los microorganismos a los 30 minutos, incluso en gérmenes multiresistentes como el SARM y el ERV y su efecto antimicrobiano se mantiene de manera continua durante 3-4 días, alcanzando niveles de concentración mínima inhibitoria (CMI) efectivos ante los microorganismos, lo que evita el riesgo posible de resistencias a la plata, que de acuerdo con la bibliografía $(2,13-15)$, podría estar relacionado con el uso de productos con baja concentración de plata.

La distribución de la plata en el apósito Acticoat ${ }^{\circledR}$ no interfiere con su liberación en el lecho lesional, circunstancia a tener en cuenta en el caso de apósitos que absorben el exudado y que por tanto, absorben la plata liberada, lo que dificulta su contacto directo con el lecho lesional.

De acuerdo con la bibliografía, la plata nanocristalina presenta también un efecto antinflamatorio (16) y permite disminuir, sin eliminarlos totalmente, los niveles de metaloproteasas (MMP), de interleukina-1 (IL-1) y de factor de crecimiento TN alfa en el lecho lesional $(17,18)$. Esto es de gran importancia ya que permite combinar el efecto antibacteriano con la creación de un entorno propicio para la cicatrización, ya que un exceso de MMP en el lecho lesional incrementa los niveles de exudado e impide una correcta cicatrización.

Desde la aparición de Acticoat ${ }^{\circledR}$ se han generado múltiples evidencias basadas en trabajos de investigación tanto "in vivo", como "in vitro": "in vitro", acerca de su eficacia antimicrobiana, así como comparaciones con otros productos para tratamiento tópico de la infección, a través de las cuales se demuestra su efectividad $(19,20)$ para eliminar cepas de microorganismos como Acinetobacter baumanii, Bacteroides fragilis, Burkholderia cepacia, Citrobacter koseri, Enterobactereicae, Enterococcus faecalis, Escherichia coli, Klebsiella pneumoniae, Proteus miriabilis, Pseudomonas aureginosa, Staphylococcus aureus. Staphylococcus aureus resistente a la meticilina (SARM), Staphylococcus epidermidis y especies de hongos cómo Aspergillus fumigatus, Candida albicans, Candida Galabrata, Candida Tropicalis y Saccharomyces cerevisiae. "In vivo", a través de ensayos clínicos y estudios comparativos que demuestran la efectividad antimicrobiana de Acticoat ${ }^{\circledR}$ frente a la solución de nitrato de plata al $0,5 \%$ (21) en pacientes con quemaduras, la eficacia de Acticoat ${ }^{\circledR}$ frente a un antibiótico tópico en pacientes con quemaduras a los que se les practicaron injertos cutáneos (22), su eficacia frente a la sulfadiazina argéntica en quemaduras en pacientes pediátricos (23), su eficacia frente a apósitos de vaselina en heridas experimentales en cerdos y su efecto antimicrobiano frente a Silvazine ${ }^{\circledR}$ (una combinación de digluconato de clorhexidina al $0,2 \%$ y sulfadiazina argéntica al 1\%) (18).

Por lo que hace referencia al dolor en las curas, existe un ensayo clínico que determina que el tratamiento de las quemaduras superficiales con Acticoat ${ }^{\circledR}$ es menos doloroso que con sulfadiazina argéntica al 1\% (24).

Por todo ello, el producto que analizaremos, es hoy en día una opción segura y eficaz para la prevención y tratamiento de la infección local en quemaduras, que no presenta los riesgos y/o inconvenientes de otras alternativas tipo antibióticos tópicos (sensibilización, resistencias) o los de otros productos con plata como la sulfadiazina argéntica (resistencias, problemas con la fracción sulfamida, necesidad de cura cada 12 horas) (17, 18. 21-25).

\section{Material y método}

Planteamos un estudio orientado a comparar la utilización en el tratamiento local de quemaduras con un apósito de plata nanocristalina frente a la utilización de sulfadiazina argéntica en base a dos objetivos:

- comparar su eficacia clínica

- comparar su coste/beneficio

Para ello, comparamos dos cohortes de pacientes con quemaduras atendidos en el Hospital General de Alicante (España), una de pacientes tratados con sulfadizaina argéntica y otra con Acticoat ${ }^{\circledR}$.

Incluimos en el estudio pacientes de ambos sexos, con quemaduras de $2^{\circ}$ ó $3^{\circ}$ grado en cualquier zona corporal, con superficie corporal quemada (SCQ) mayor del $5 \%$ y que requirieron ingreso hospitalario para tratamiento. Excluimos aquellos pacientes alérgicos a los compuestos con plata y aquellos que no reunían criterios de ingreso hospitalario. 
Definimos las siguientes variables para comparar las dos cohortes de pacientes:

- Tiempo necesario para la epitelización de las quemaduras

- Tiempo de ingreso

- Tiempo de atención extrahospitalaria hasta la epitelización de las quemaduras

- Episodios de bacteriemia clínica

- Número de pacientes que precisaron antibioticoterapia

- Número total de curas durante el tratamiento hospitalario

- Número total de curas durante el tratamiento extrahospitalario

- Número total de curas necesario para conseguir la epitelización de las quemaduras

\section{PROTOCOLO}

Como protocolo de tratamiento de las quemaduras en nuestra Unidad de Quemados, hemos seguido la siguiente pauta de forma general:

\section{Medidas generales:}

- Criterios de ingreso hospitalario:

Quemaduras $2^{\circ}$ grado con más del $15 \%$ SCQ (>10\% niños)

Quemaduras $3^{\circ}$ grado con más del 2\% SCQ

Quemaduras en cara, manos, pies, periné o genitales.

Existencia de lesiones concomitantes graves

Quemaduras eléctricas o químicas

Quemaduras circulares

Quemaduras con inhalación de humos

Existencia de patología previa grave

- Cuidados generales:

Reposición de líquidos

Tratamiento del dolor

Profilaxis antitrombótica

Profilaxis de úlcera de Curling

Profilaxis antitetánica

Oxigenoterapia

- Aislamiento del paciente en un entorno aséptico: habitaciones individuales dentro de una Unidad de Quemados cerrada, con pasillos limpio y sucio separados para mayor aislamiento.

- Manipulación estéril de las quemaduras durante las curas por parte del personal médico y de enfermería.

- Curas en sala dentro de la Unidad de Quemados mediante sistema de baños por arrastre en tanque de Hubbard.

- Tratamiento quirúrgico en quirófano de la misma Unidad. Desbridamientos o escarectomías precoces, entre los 3 y 5 días de ingreso hospitalario. Aposición de injertos cutáneos autólogos o sintéticos (Biobrane $\left.{ }^{\circledR}\right)$ en la primera escarectomía o en las sucesivas.
- De entrada no utilizamos antibióticos sistémicos profilácticos, salvo en quemaduras de varios días de evolución con signos locales o sistémicos de infección y en quemaduras eléctricas.

- Profilaxis antibiótica con cloxacilina intravenosa (IV), $2 \mathrm{gr}$. en adultos y $0,05 \mathrm{gr} / \mathrm{kg}$ en niños, 1 hora antes de los procedimientos de cura o desbridamiento cruentos que impliquen sangrado con posibilidad de bacteriemia.

En pacientes alérgicos a beta-lactámicos, empleamos ciprofloxacina 500mg IV o vancomicina $1 \mathrm{gr}$.

- Toma de vía venosa periférica para la infusión de líquidos de reposición como primera alternativa. Cuando resulte imposible o en pacientes con grandes demandas (hemoderivados, nutrición parenteral, etc.), se toma vía venosa central.

- Sonda vesical para control de diuresis

- Sonda nasogástrica en casos de íleo paralítico.

\section{Medidas locales:}

- Limpieza de la quemadura con solución antiséptica tipo clorhexidina $0,5 \%$.

- Desbridamiento de ampollas y flictenas en condiciones de máxima esterilidad.

- Cura limpia de la quemadura con apósito vaselinado hasta revisión en 12-24 h.

- Curas sucesivas con pomada de sulfadiazina argéntica al $1 \%$ cada $12 \mathrm{~h}$, aplicada en capa de $3 \mathrm{~mm}$. y cubierta por gasa o compresa estéril y vendaje elástico.

- Curas sucesivas con apósito de plata nanocristalina (Acticoat $\left.{ }^{\circledR}\right)$ previamente sumergido en agua destilada estéril y aplicado directamente sobre la quemadura o separado por un apósito siliconado para evitar adherencias. Cobertura con gasa o compresa estéril y vendaje elástico. Las curas con plata nanocristalina se cambian cada 3 días para control de la herida y diariamente se humedecen con agua destilada sin cambio del apósito.

- Control bacteriológico semanal del exudado o de la escara de la quemadura mediante cultivos cualitativos y cuantitativos.

\section{ANÁLISIS DE DATOS}

Para el análisis estadístico utilizamos estadísticos descriptivos así como pruebas para la comparación de grupos, en el caso de variables cualitativas mediante la Chi cuadrado de Pearson y en el caso de las variables cuantitativas la prueba no paramétrica de Mann-Whitney.

\section{Resultados y casos}

Incluimos en el estudio un total de 38 pacientes, 26 hombres $(68 \%)$ y 12 mujeres (31\%), distribuidos en 2 grupos: Grupo 1 con 22 pacientes (13 hombres y 9 mujeres) tratados con un apósito de plata nanocristalina APNC $(57,9 \%)$ frente al Grupo 2 de 16 pacientes 
Tabla I: Variables de comparación inicial entre los dos grupos de estudio

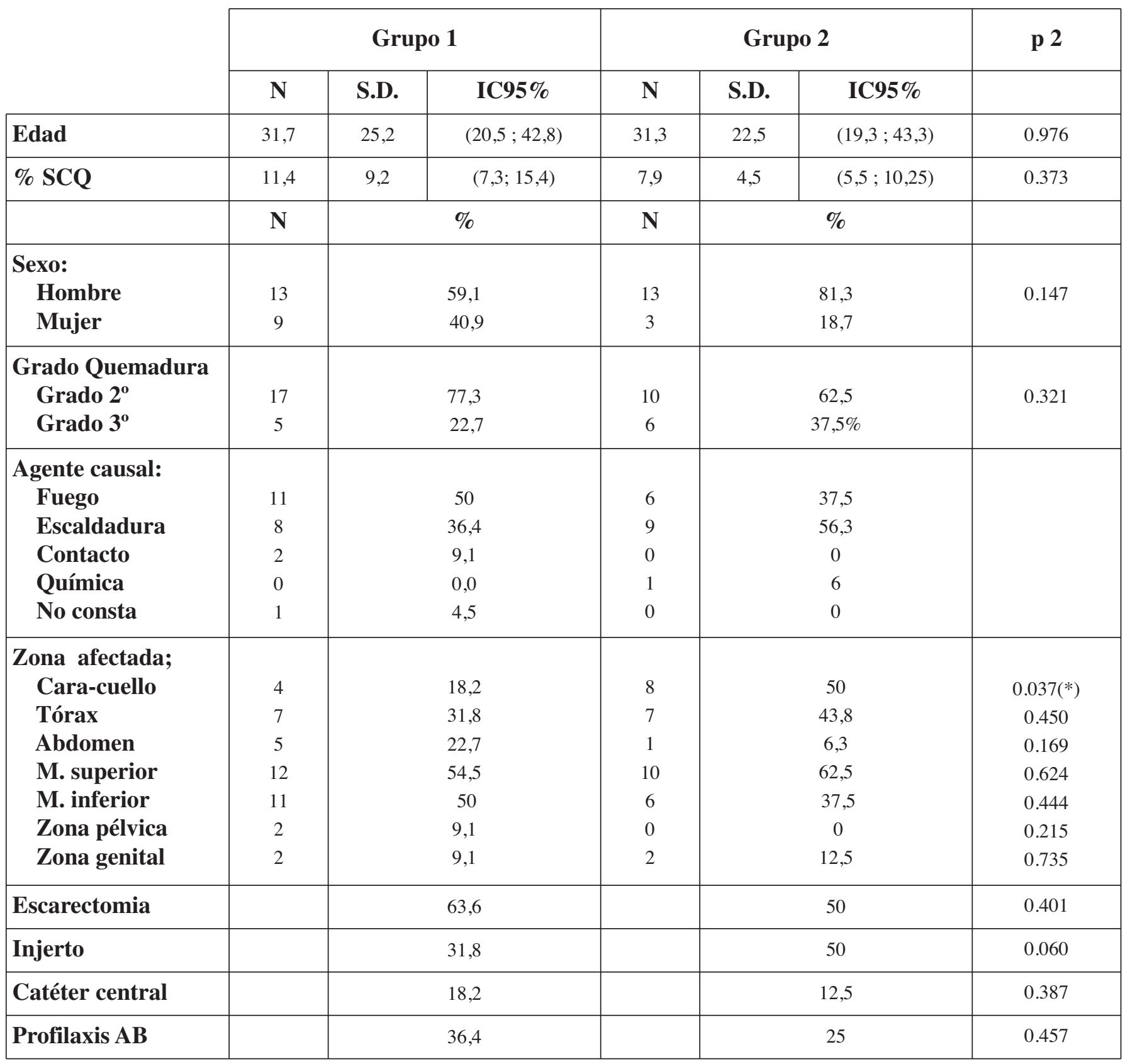

SCQ: superficie corporal quemada; Profilaxis AB: profilaxis antibiótica; Grupo 1 APNC: Acticoat $®$ plata nanocristalina; Grupo 2 SDA: sulfadiazina argéntica

(13 hombres y 3 mujeres) tratados con sulfadiazina argéntica SDA $(42,1 \%)$.

La edad media para el Grupo 1 APNC, fue 31,7 años con una desviación estándar de 25,2 y con intervalo de confianza del 95\% (20,5 - 42,8); en el Grupo 2 la edad media fue 31,3 años con una desviación estándar de 22,5 y con intervalo de confianza del $95 \%$ (19,3$43,3)$.

La SCQ fue del 11,4\% en el Grupo 1 y del 7,9\% para el Grupo 2. El agente causante de la quemadura más frecuente fue el fuego, seguido de la escaldadura. Un $31 \%$ de los pacientes del Grupo 1 requirió la realización de injertos de piel frente a un 50\% del Grupo 2, sin que esto resultara ser una diferencia significativa $(\mathrm{p} 0,060)$; los 2 grupos llevaron vías centrales: $18 \%$ en el Grupo 1 (Acticoat ${ }^{\circledR}$ ) y $12,5 \%$ en el Grupo 2 , sin ser este dato tampoco significativo.

En resumen, no encontramos diferencias estadísticamente significativas en relación con las variables descriptoras de los pacientes (Tabla I).

La única variable que sí mostró diferencias entre lo grupos fue la localización de la quemadura en zona facial, que estaba afectada en el 18\% en el Grupo 1 y en el $50 \%$ en el Grupo 2

En la comparación sobre eficacia clínica de los dos compuestos, no hallamos diferencias estadísticamente significativas en el tiempo para la completa epitelización de las quemaduras: en el Grupo 1 fue de 29,8 días, con 
Tabla II: Variables relacionadas con la eficacia clínica

\begin{tabular}{|l|c|c|c|c|c|c|c|}
\cline { 2 - 7 } \multicolumn{1}{c|}{} & \multicolumn{3}{c|}{ Grupo 1 } & \multicolumn{3}{c|}{ Grupo 2 } & \multirow{2}{*}{ p 2 } \\
\cline { 2 - 7 } \multicolumn{1}{c|}{} & Media & S.D. & IC95\% & Media & S.D. & IC95\% & \\
\hline $\begin{array}{l}\text { Epitelización } \\
\text { TEP }\end{array}$ & 29,8 & 16,31 & $(22,38 ; 37,23)$ & 32,25 & 19,77 & $(21,71 ; 42,78)$ & 0,683 \\
\hline & \multicolumn{3}{|c|}{$\%$} & \multicolumn{3}{c|}{$\%$} & \\
\hline Bacteriemia & \multicolumn{3}{|c|}{36,4} & \multicolumn{3}{c|}{37,5} & 0,943 \\
\hline AB & \multicolumn{3}{|c|}{40,9} & 31,3 & 0,542 \\
\hline
\end{tabular}

Grupo 1 APNC: Acticoat $®$ plata nanocristalina; Grupo 2 SDA: sulfadiazina argéntica.

S.D. Desviación estándar, IC95\% intervalo de confianza del $95 \%$

TEP:Tiempo para la completa epitelización de las quemaduras; Bacteriemia: pacientes con episodios de bacteriemia clínica; AB: pacientes que han precisado tratamiento antibiótico.

Tabla III: Variables relacionadas con la dimensión coste/beneficio

\begin{tabular}{|c|c|c|c|c|c|c|c|}
\hline & \multicolumn{3}{|c|}{ Grupo 1} & \multicolumn{3}{|c|}{ Grupo 2} & \multirow[t]{2}{*}{$\mathbf{p}$} \\
\hline & Media & S.D. & IC95\% & Media & S.D. & IC95\% & \\
\hline Hospitalización & 11,2 & 8,5 & $(7,4 ; 14,9)$ & 12,37 & 11,3 & $(6,4 ; 18,4)$ & 0,836 \\
\hline $\begin{array}{l}\text { Curas } \\
\text { Hospital (*) }\end{array}$ & 3,43 & 2,27 & $(2,39 ; 4,46)$ & 24,75 & 22,54 & $(12,73 ; 36,76)$ & 0,01 \\
\hline \begin{tabular}{|l|} 
Curas \\
Consultas(**)
\end{tabular} & 5,09 & 4,34 & $(3,11 ; 7,07)$ & 19,87 & 13,45 & $(12,68 ; 27,06)$ & 0,01 \\
\hline Curas Totales & 8,52 & 4,53 & $(6,45 ; 10,58)$ & 44,62 & 29,12 & $(29,05 ; 60,19)$ & 0,01 \\
\hline \begin{tabular}{|l|} 
Días de \\
Tratamiento
\end{tabular} & 18,6 & 15,72 & $(11,5 ; 25,6)$ & 19,87 & 13,49 & $(12,68 ; 27,06)$ & 0,656 \\
\hline
\end{tabular}

Grupo 1:APNC: Acticoat $\circledast$ plata nanocristalina; Grupo 2: SDA: sulfadiazina argéntica

Curas Hospital: número de curas durante la hospitalización. (*) Una cada 3-4 días grupo1. Dos al día grupo 2

Curas consultas: número de curas extrahospitalarias hasta la completa epitelización (**), Una cada 3-4 días los del grupo 1. Una al día los de grupo 2.

Curas totales: número total de curas hospitalarias y extrahospitalarias hasta la completa epitelización.

Días de Tratamiento: días de tratamiento extrahospitalario hasta la completa epitelización.

una desviación estándar de 16,31 y un intervalo de confianza del 95\% (22,38-37,25) y en el Grupo 2 fue de 32,25 días, con una desviación estándar de 19,77 y un intervalo de confianza de del 95\% ( $21,71-42,78)$.

El porcentaje de pacientes con episodios de bacteriemia clínica fue del $36 \%$ y $37 \%$ respectivamente y el número de pacientes que precisaron tratamiento antibiótico fue de 9 pacientes en el Grupo 1 y 5 pacientes en el Grupo 2 (Tabla II).

En el estudio de coste/beneficio, tampoco hallamos diferencias estadísticamente significativas para las variables de hospitalización, 11,2 días de media para el Grupo 1 y 12,37 días para el Grupo 2 así como en los días de tratamiento extrahospitalario hasta la completa epitelización (Tabla III).

Sin embargo, encontramos diferencias significativas a favor del Grupo1 ( Plata nanocristalina) para las variables de número de curas durante la hospitalización: 3,43 curas de media durante su ingreso para el Grupo1 frente a 24,75 curas para el Grupo 2; número de curas extrahospitalarias hasta la completa epitelización: 5,09 curas de media en consulta externa para el Grupo1 frente 19,87 curas para el Grupo 2; y número total de curas hasta la completa epitelización: 8,52 curas de media hasta la epitelización para el Grupo1 frente a 44,62 curas para el Grupo 2 (Tabla III).

Los casos que reseñamos y las fotografías son de pacientes del grupo de tratamiento con plata nanocristalina y representan las posibles variables clínicas. En los 2 primeros, los agentes más frecuentes; en el tercero, un caso pediátrico; en el $4^{\circ}$ y en el $5^{\circ}$, escarectomías en un hombre y una mujer; en el $6^{\circ}$, injertos laminares; en el $7^{\circ}$, injertos mallados en un adulto y en el $8^{\circ}$ injertos mallados en un caso pediátrico. No hemos tenido ningún caso de alergia a la plata, ni de tatuajes a largo plazo

Caso 1: Varón de 32 años con $18 \%$ de SCQ, profundidad $2^{\circ}$ grado, en miembro superior derecho y tórax, por accidente doméstico (escaldadura); 3 curas y 12 días para su epitelización con ingreso hospitalario de 4 días (Fig. 2). 


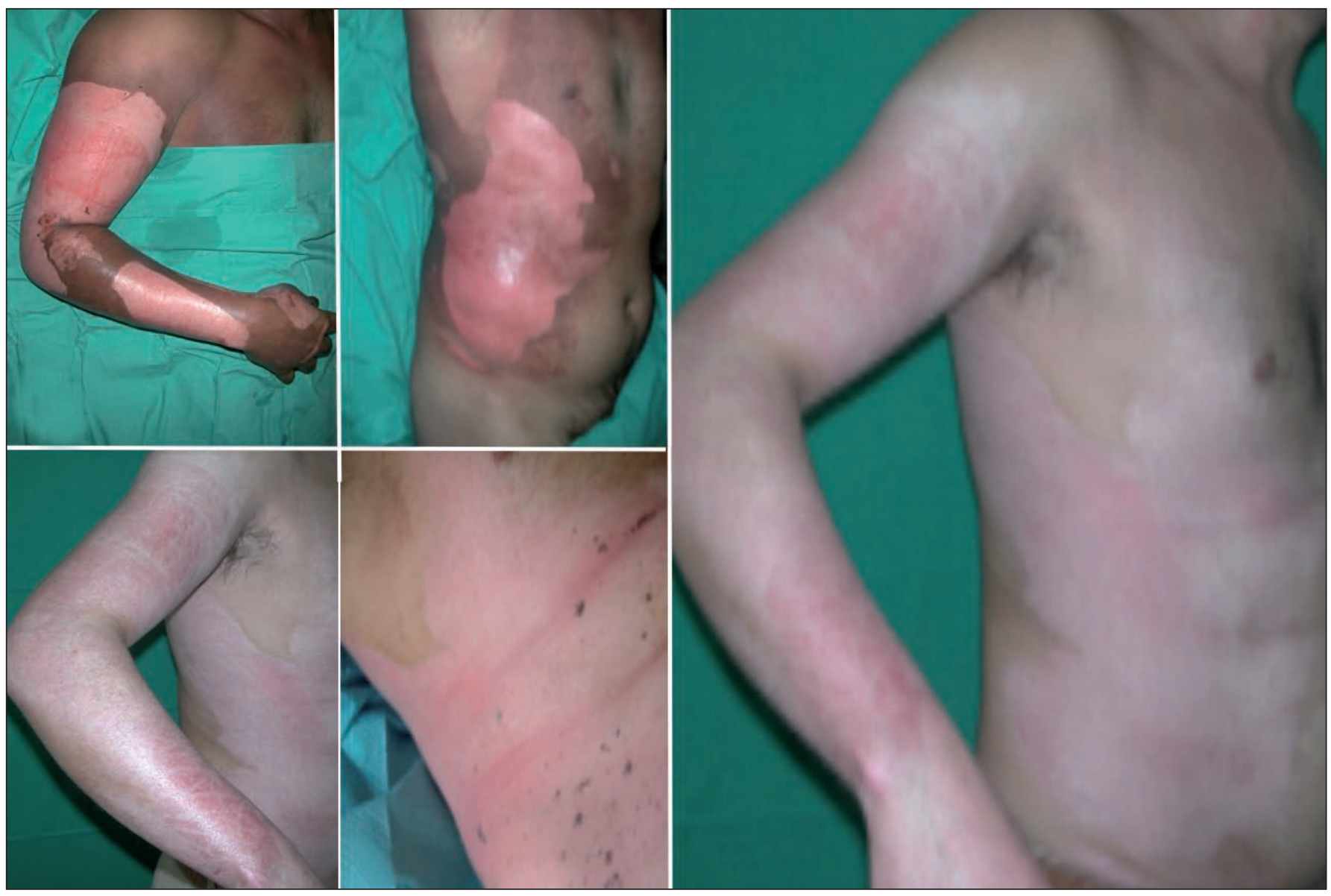

Fig. 2: Varón de 32 Años con $18 \%$ de SCQ, $2^{\circ}$ grado, escaldadura. A y B al ingreso, C y D al alta tras 12 días de evolución. E resultado a los 3 meses.

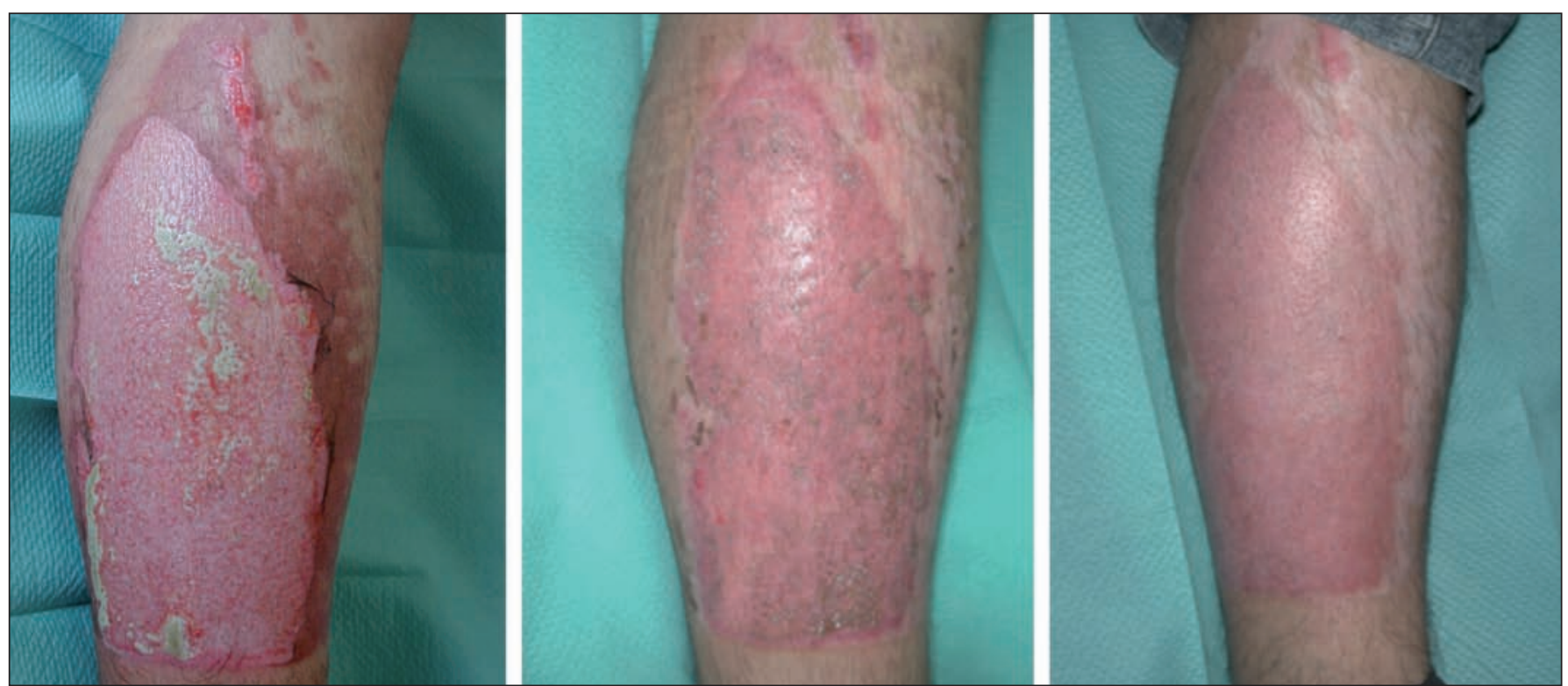

Fig. 3: Varón de 28 Años con $10 \%$ SCQ, $2^{\circ}$ grado, miembro inferior derecho. Agente fuego. A al ingreso. B cura tras 20 días de evolución y C resultado a los 2 meses.

Caso 2: Varón de 28 Años con que quemadura del $10 \%$ de SCQ en miembro inferior derecho, $2^{\circ}$ grado y en tórax superficial, más sospecha de inhalación de humos por accidente domestico (fuego); 5 curas y 20 días para su epitelización con ingreso hospitalario de 6 días (Fig. 3).

Caso 3: Lactante varón de 18 meses de edad que ingresa con quemaduras por escaldadura tras accidente doméstico, con un $8 \%$ de SCQ afectando a miembros inferiores y área genital de $2^{\circ}$ grado; valoración por asuntos sociales. Requirió 7 curas para su epitelización y 21 días de ingreso hospitalario (Fig. 4).

Caso 4: Varón de 33 años de edad con 5\% de SCQ en miembro superior izquierdo, $2^{\circ}$ grado profundo por accidente laboral (fuego); 8 curas, quirófano para escarectomía conservadora y 25 días para su epitelización, con ingreso hospitalario de 10 días (Fig. 5). 

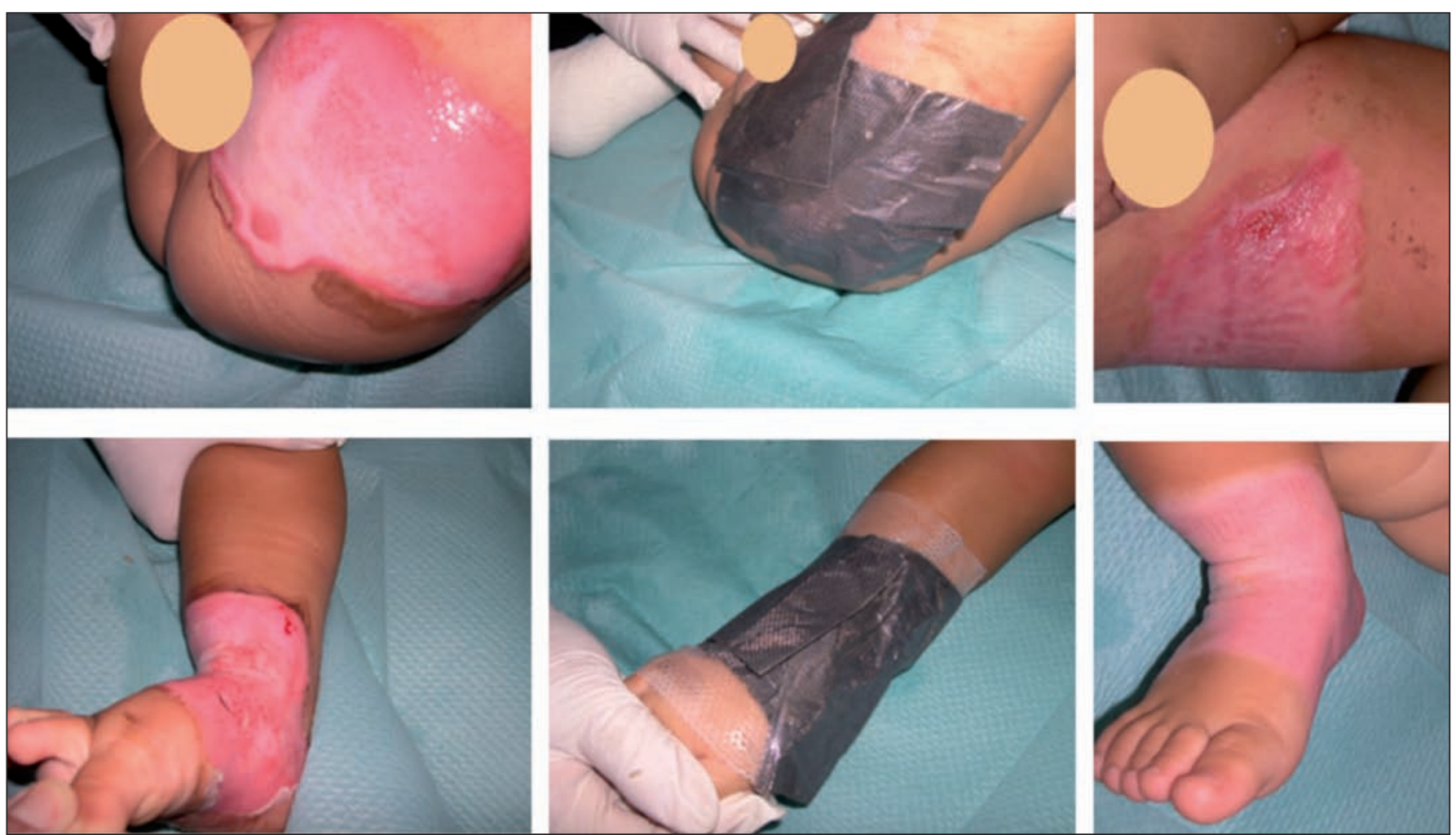

Fig. 4: Lactante varón de 18 meses con $8 \%$ de SCQ en miembros inferiores y área genital, $2^{\circ}$ grado por escaldadura. Precisó para epitelización 21 días.

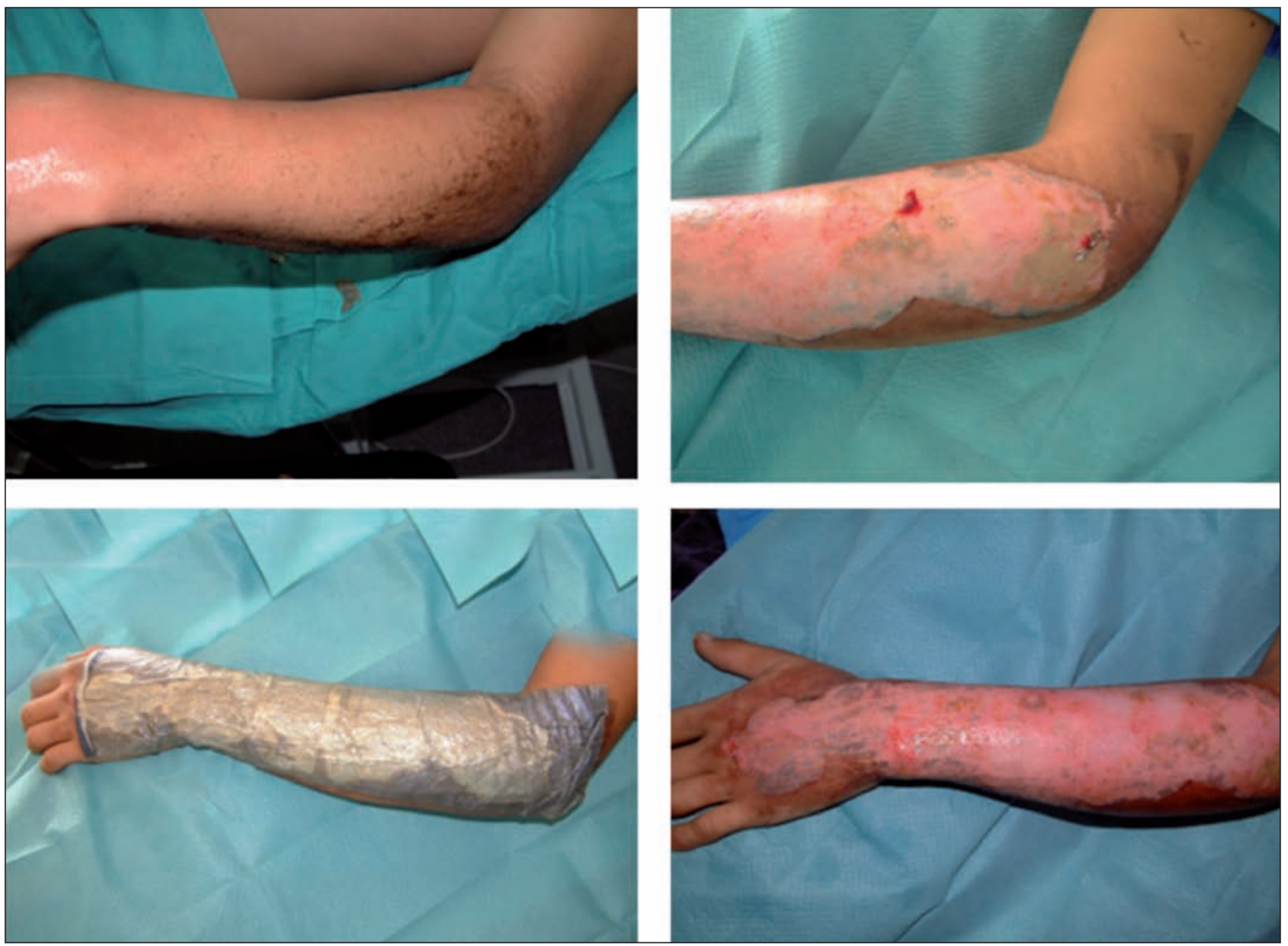

Fig. 5: Varón de 33 años de edad con $5 \%$ de SCQ en miembro superior izquierdo, $2^{\circ}$ grado profundo, agente fuego. A al ingreso. B cura a los 7 días de evolución y $\mathrm{C}$ con el apósito puesto. D, resultado precoz y escarectomía conservadora. 

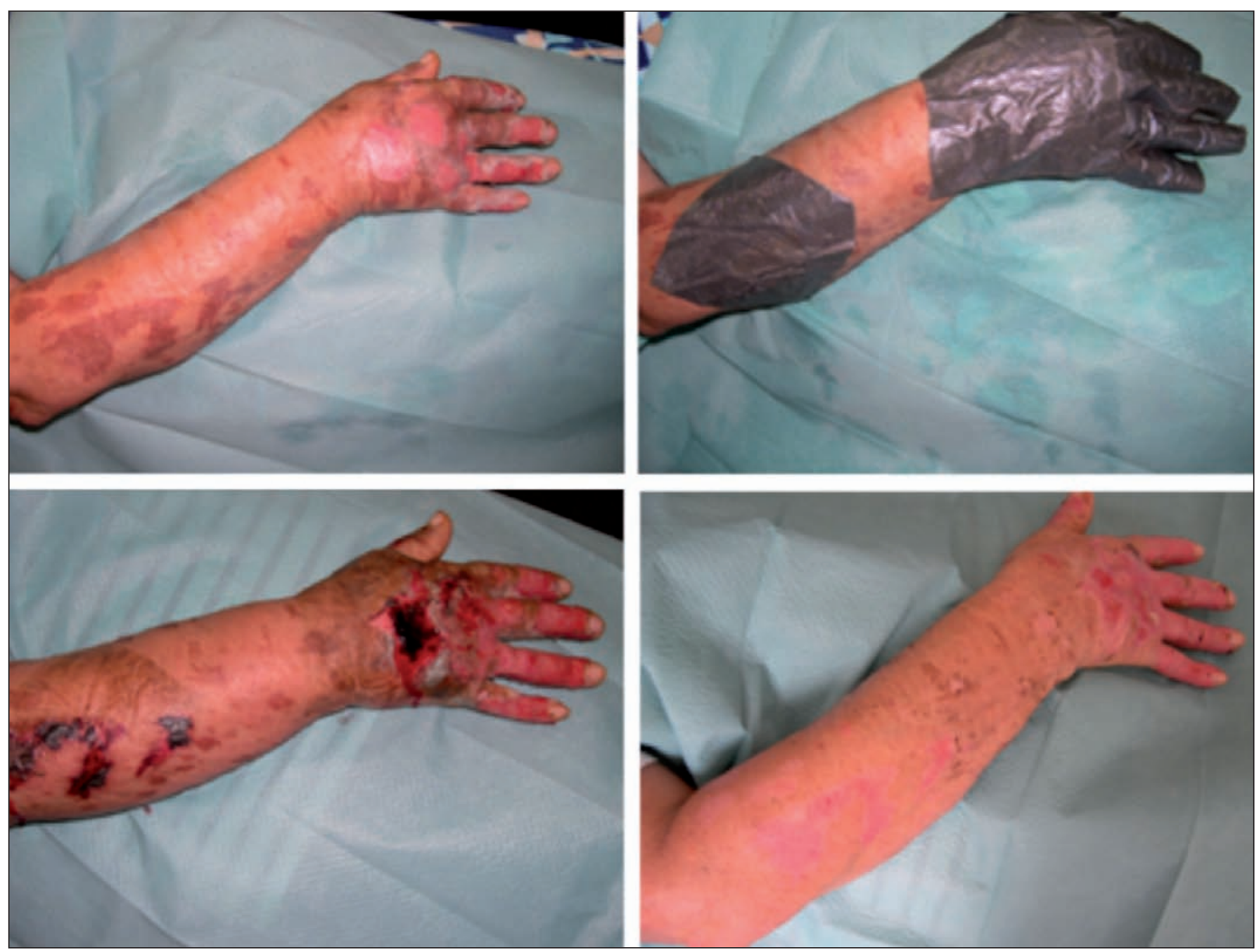

Fig. 6: Mujer 56 años con quemaduras en miembro superior y en mano de $2^{\circ}$ grado profundo debido a quemadura por escaldadura con cera. Precisó 16 días de evolución para epitelización. Nótese la adaptabilidad de Acticoat $\circledast$ a la mano y dedos.

Caso 5: Mujer 56 de años de edad con 3\% de SCQ en miembro superior y mano, $2^{\circ}$ grado profundo, quemadura por escaldadura con cera de depilar producida en accidente laboral; 6 curas y 16 días de evolución para su epitelización, con ingreso hospitalario de 5 días (Fig. 6).

Caso 6: Varón de 26 años con quemaduras del 20\% de SCQ en miembro inferior, de tercer grado y en espalda y manos. Las quemaduras se produjeron por fuego con gasolina en un accidente laboral. Quirófano bajo anestesia para escarectomía con dermatomo en miembro inferior; 18 días de ingreso hospitalario, bacteriemia por SAMR y 26 días de evolución para epitelización total (Fig. 7).

Caso 7: Varón de 65 años con quemaduras del $25 \%$ de SCQ en miembros inferiores, de tercer grado y en manos. Las quemaduras se produjeron por fuego con gasolina en accidente doméstico. Quirófano en dos ocasiones bajo anestesia para escarectomía con dermatomo en miembros inferiores e injertos mallados. Un total de 31 días de ingreso hospitalario hasta epitelización total (Fig. 8 y 9 ).

Caso 8: Escolar de 5 años de edad que ingresa por quemaduras por escaldadura con un $45 \%$ de SCQ, tercer grado en su mayoría y desnutrición; valoración por asuntos sociales con diagnostico de maltrato infantil. Requirió 2 intervenciones para escarectomía, 1 para injertos mallados, nutrición parenteral y 2 meses de ingreso hospitalario (Fig. 10).

\section{Discusión}

Los 2 grupos estudiados mostraron ser muy homogéneos en cuanto a sus características clínicas: edad, distribución entre hombres y mujeres, porcentaje de SCQ, profundidad de la quemadura, agentes etológicos y necesidad de tratamiento quirúrgico para escarectomías o escarectomías con áreas injertadas. Solo observamos diferencia en ambos grupos en cuanto a la localización de las quemaduras en la zona facial, con mayor incidencia en el Grupo 2 (sulfadiazina argéntica). Esto se explica por un sesgo de selección según el protocolo de actuación en nuestra Unidad de Quemados, ya que en este tipo de localización preferimos utilizar un tipo de cura expositiva vaselinada o bien a base de sulfadiazina argéntica, y no solemos utilizar casi nunca el apósito de plata en esta zona, a excepción del cuello; este hecho hace que ambos grupos no sean comparables para este área. 


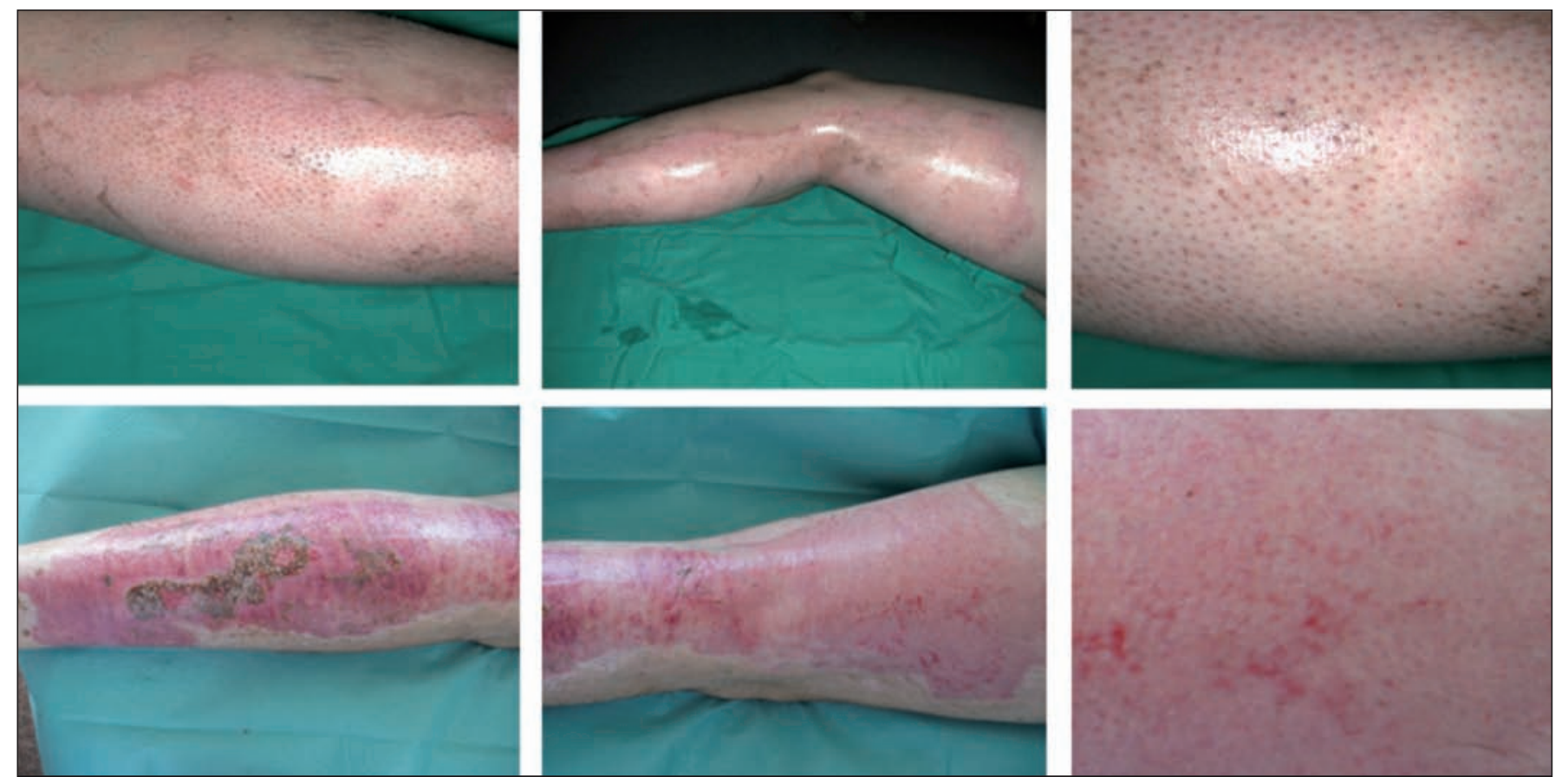

Fig. 7: Varón de 26 años con quemaduras en miembro inferior de tercer grado profundo por fuego (gasolina). Escarectomía con dermatomo. 26 días de evolución para epitelización.

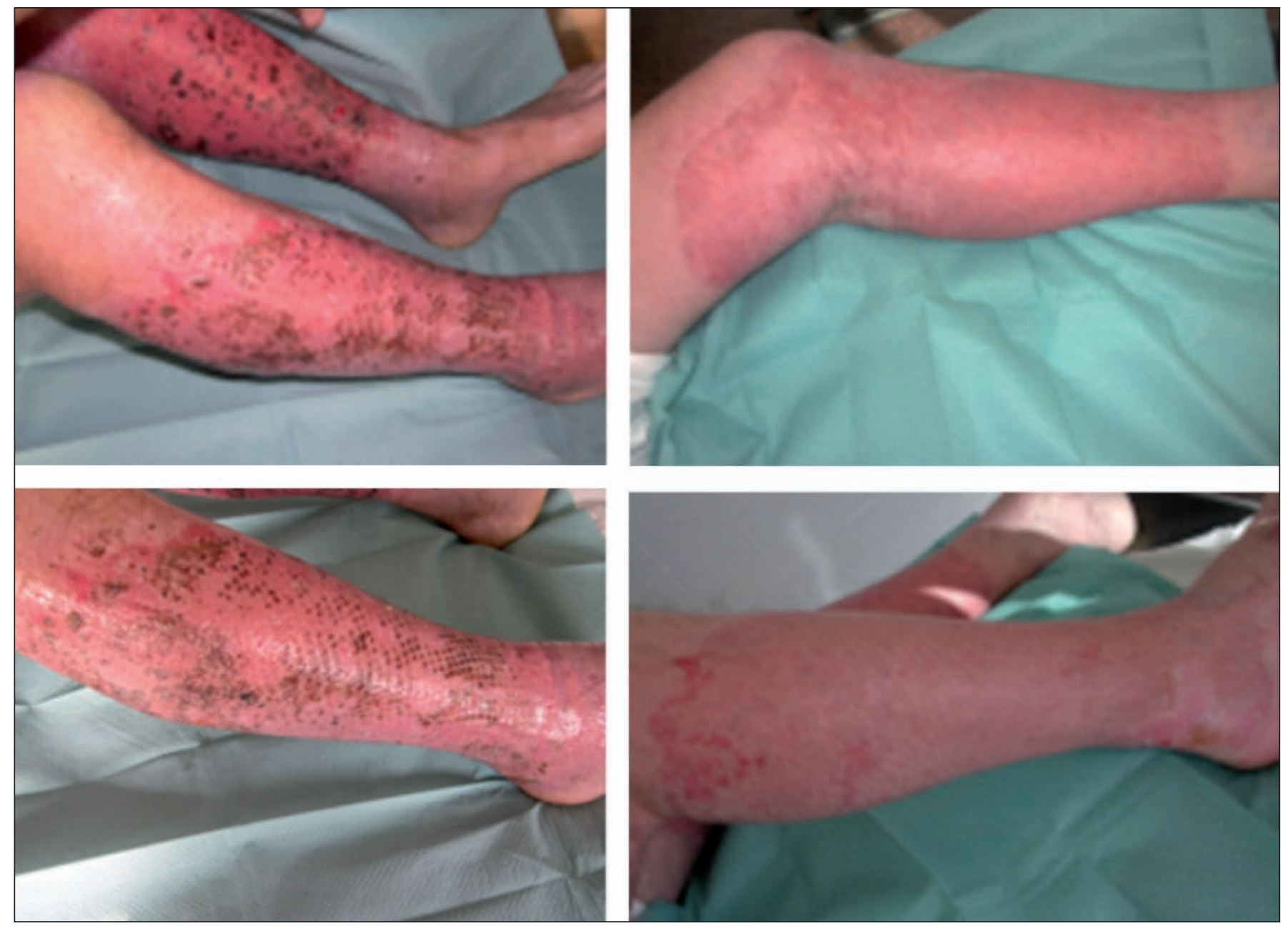

Fig. 8: Varón de 65 años con $25 \%$ de SCQ en miembros inferiores, tercer grado. Injertos mallados con Acticoat $®$. 


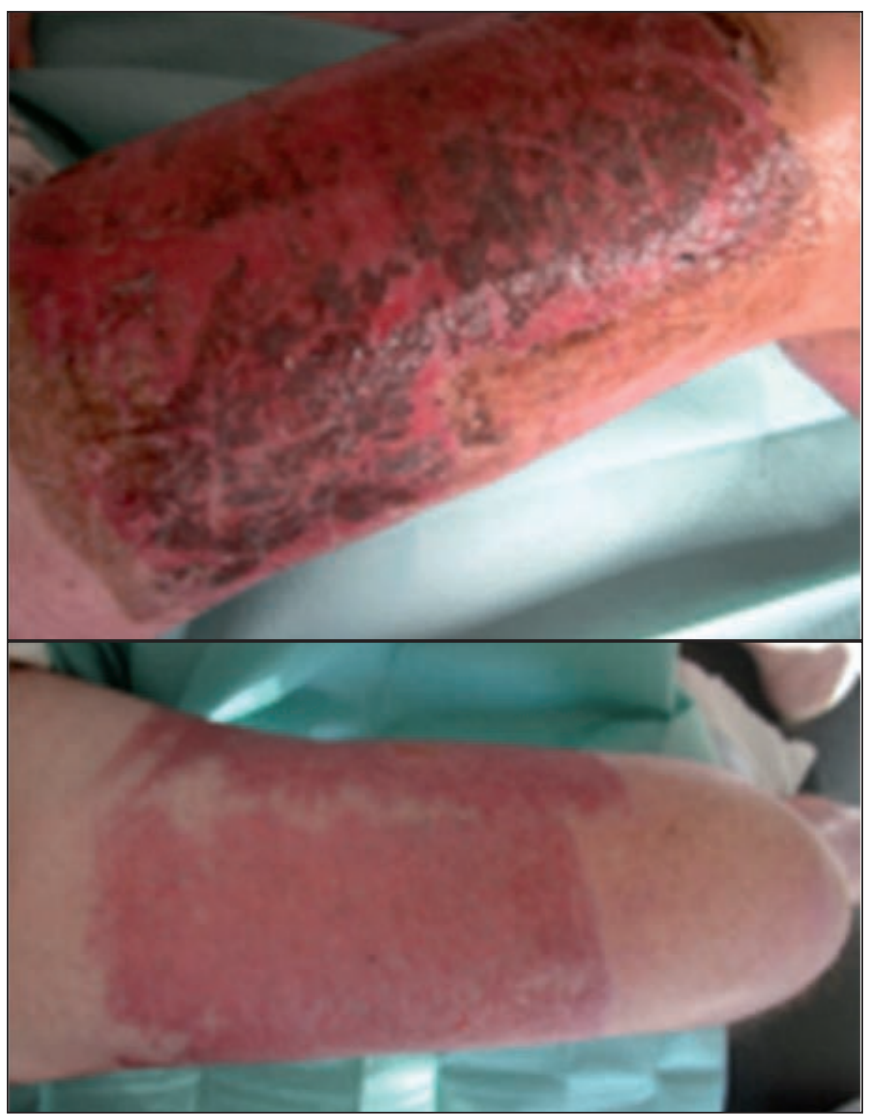

Fig. 9: Acticoat $₫$ en zona donante.

Podemos interpretar que se trata de una población adulta joven con quemaduras intermedias; no son severas, pero sí lo suficientemente importantes para requerir ingreso hospitalario y tratamiento en Unidad de Quemados. En su evolución, más de la mitad de los pacientes necesitó tratamiento quirúrgico para limpieza y posterior aposición de injertos de piel. Son por tanto quemaduras que necesitan atención médica especializada, que por su grado de profundidad y extensión necesitan un primer periodo de hospitalización y un segundo periodo de trata- miento ambulante hasta su completa epitelización, lo que obliga a un control en consulta externa hospitalaria. La curación de las quemaduras ocasionará en la mayoría de los casos secuelas cicatriciales en un grupo poblacional joven en el que pueden tener repercusión funcional o psicológica.

Con respecto a los resultados de eficacia clínica, observamos que los 2 compuestos resultan igual de eficaces respecto a las variables clínicas analizadas. Los periodos totales necesarios para la completa epitelización de las quemaduras son similares y la capacidad bactericida y bacteriostática de ambos compuestos de plata se muestra también similar a la hora de controlar las bacteriemias sistémicas (en ambos grupos, un tercio de los pacientes presentaron episodios de bacteriemia que requirieron tratamiento antibiótico sistémico).

Para el estudio de coste/beneficio, utilizamos en ambos grupos índices indirectos de gasto. Creemos que los mejores índices indirectos son el número de curas necesario hasta la completa curación, por cuanto requieren de material, atención de enfermería y vigilancia médica, y el tiempo total hasta la completa epitelización, puesto que supone el periodo en que el paciente permanecerá de baja laboral. En este sentido, tanto el grupo con Acticoat ${ }^{\circledR}$ como el de sulfadiazina argéntica mostraron la misma estancia hospitalaria y los mismos periodos de curación; es decir, ninguno de los 2 grupos acortó el tiempo de tratamiento hospitalario ni extrahospitalario. Pero sí que observamos diferencias muy importantes en cuanto a las curas realizadas, tanto a nivel hospitalario como a nivel extrahospitalario, siendo el número de curas en el segundo grupo (sulfadiazina) 6 veces superior al del grupo tratado con Acticoat ${ }^{\circledR}$. Si interpretamos que el gasto en atención hospitalaria (médica y de enfermería) y el gasto por baja laboral son similares en los dos grupos, la diferencia entre ambos vendrá expresada en el gasto que originen las curas, que es realmente lo que los diferencia.

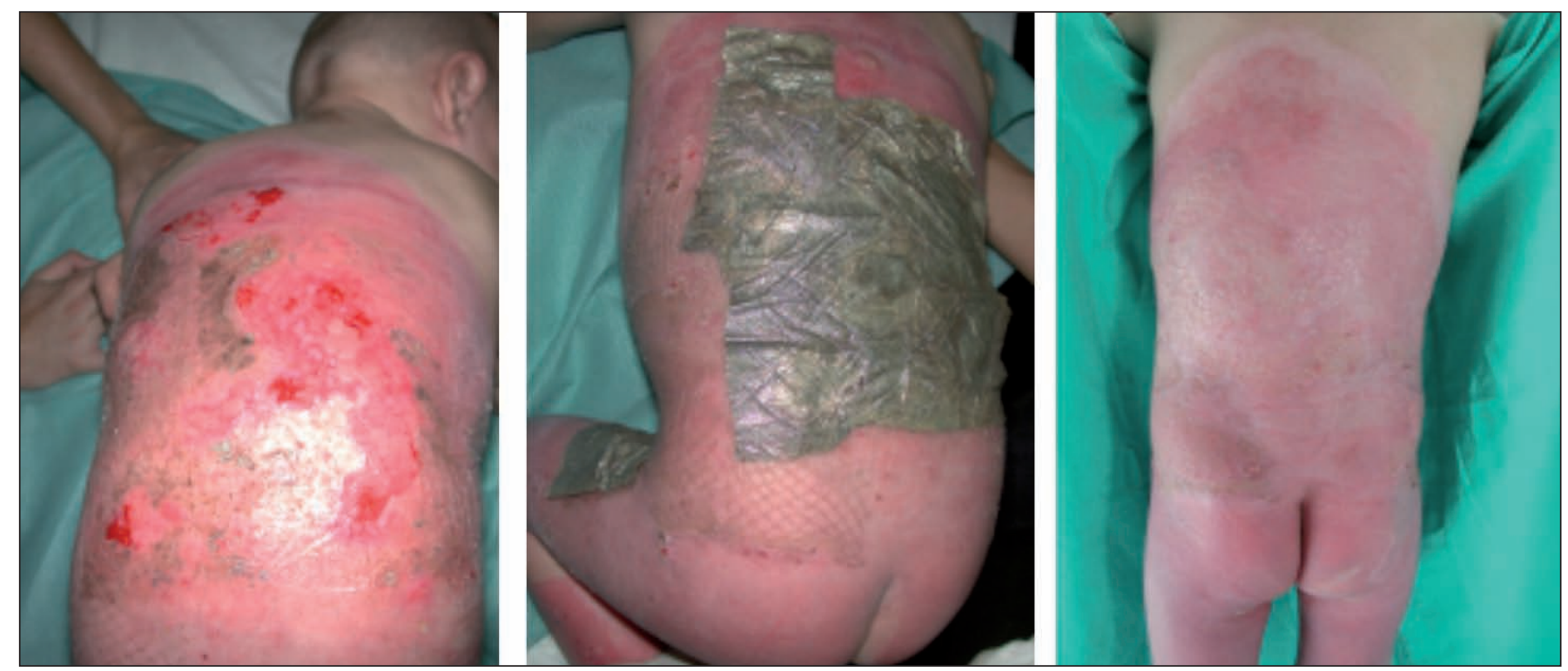

Fig. 10: Varón de 5 años con quemaduras de tercer grado en espalda por escaldadura. Injertos mallados con Acticoat $®$. 
Por lo que hace referencia al dolor en las curas, existe un ensayo clínico que determina que el tratamiento de quemaduras superficiales con Acticoat $\AA$ es menos doloroso que el realizado con sulfadiazina argéntica al $1 \%$ (24) y aunque no ha sido uno de los objetivos de nuestro estudio, podríamos deducir que el menor número de curas necesarias con Acticoat ${ }^{\circledR}$ también puede contribuir a disminuir el dolor y la necesidad de medicación analgésica, así como la ansiedad que generan las curas (cada 12 horas en el caso de la sulfadiazina argéntica) en el paciente. Por otro lado, cuantas menos curas sean necesarias, menor tiempo de dedicación de enfermería y menor gasto en horas de enfermería serán necesarios, lo que permitirá tratar ambulatoriamente una mayor SCQ.

Probablemente el tipo de patología en general sobre la que actualmente existen más evidencias acerca de la efectividad de la plata nanocristalina sean las quemaduras. Disponemos de ensayos clínicos y estudios comparativos que demuestran la efectividad antimicrobiana de Acticoat ${ }^{\circledR}$ frente a la solución de nitrato de plata al 0,5\% $(20,21,24)$ en pacientes con quemaduras, sobre la eficacia de Acticoat ${ }^{\circledR}$ frente al uso de antibiótico tópico en pacientes con quemaduras a los que se les ha practicado injerto cutáneo (22), sobre la eficacia de Acticoat ${ }^{\circledR}$ frente a sulfadiazina argéntica en quemaduras en pacientes pediátricos (23), sobre la eficacia de Acticoat ${ }^{\circledR}$ frente al uso de apósitos de vaselina en heridas experimentales en cerdos y sobre el efecto antimicrobiano de Acticoat ${ }^{\circledR}$ frente a Silvazine ${ }^{\circledR}$ (una combinación de digluconato de clorhexidina al 0,2\% y Sulfadiazina Argéntica al 1\%) (18).

Por lo que hace referencia a la toxicidad e hipersensibilidad frente a la plata en humanos, es muy baja y estaría en directa relación a la larga exposición a sales de plata (trabajadores de la industria fotográfica) o bien a productos prácticamente en desuso como el nitrato de plata (10), no existiendo en la práctica clínica problemas relevantes de hipersensibilidad o citotoxicidad relacionados con la utilización de apósitos liberadores de plata.

Nuestros resultados confirman que actualmente la utilización de este apósito en el tratamiento de pacientes con quemaduras, tanto adultos $(17,18,21,22,24,25)$, como pediátricos $(18,23,25)$, con injertos (17) o zonas donantes (24), ha demostrado un papel importante en nuestra practica clínica al ser una opción segura y eficaz para el tratamiento tópico de los pacientes quemados, necesitando un menor número de curas y por lo tanto, aportando la consecuente disminución de dolor a nuestros pacientes.

\section{Conclusiones}

Del estudio de comparación entre los apósitos de plata nanocristalina y la pomada de sulfadiazina argéntica podemos concluir que no hemos encontrado ninguna diferencia en cuanto a eficacia clínica en ambos grupos; siendo los periodos de hospitalización y de control extrahospitalario similares en ambos. En el mismo sentido, el control de la infección sistémica (bacteriemia) ha resultado similar con los dos grupos estudiados, demostrando una cobertura de amplio espectro para los gérmenes colonizadores de la quemadura

Si bien, ni el tiempo de hospitalización ni el de epitelización disminuyen, la espectacular reducción del número de curas (45 a 9) necesarias hasta la completa reepitelización de la quemadura, hacen que la relación coste/beneficio se decante a favor del grupo tratado con plata nanocristalina

Esto, indirectamente se traducirá en un menor gasto en atención de enfermería y en material de curas, una mayor comodidad para el paciente por la disminución del dolor y la ansiedad en las curas y una disminución de la necesidad de medicación analgésica para el tratamiento, así como una disminución del número de curas hasta la completa epitelización

\section{Dirección del autor}

Dr. José Francisco Salvador Sanz

Hospital General Universitario de Alicante. $3^{\circ}$ planta, Cirugía Plástica.

Calle Maestro Alonso s/n

03010 Alicante. España

e-mail: salvador@umh.es

\section{Bibliografía}

1. Glen Mayhall C.: "The Epidemiology on Burn Wound Infectins: Then and Now". Healthcare epidemiology. 2003:37: 543 .

2. Sittig, K.: "Effect Of Bacteriemia On Mortality After Thermal Injury", Archives Of Surgery,1988, 23:123.

3. Saffle JR, Davis B. Wialliams P.: "Recent outcomes in the treatment of burn injury in the United States". J Burn Care Rehabil $1993,16: 219$.

4. Novo Torres A., Salvador Sanz JF., Merino E.: "Incidencia de bacteriemias en pacientes quemados con y sin profilaxis antibiótica y cambios en la flora bacteriana de la escara". Presentado en la V Reunión de la Sociedad Valenciana de Cirugía Plástica. 2005.

5. Wibbenmeyer $\mathbf{L}$ et al.: "Prospective Analisis of Nosocomial Infection Rates, Antibiotic Use, and Patterns of Resistance in a Burn Population”. J Burn Care \& Res. 2006; Vol 27(2): 152.

6. Pruitt BA, McManus AT, Kim SH, Goodwin CW.: "Burn Wound Infections: Current Status". World J Surg. 1998, 22(2):135.

7. Erol S, Altoparlak U, Akcay MN, Celebi F, Parlak M.: "Changes of microbial flora and wound colonization in Burneo patients". Burns. 2004, 30(4):357.

8. Klasen HJ.: "A historical review of the use of silver in the treatment of burns. I. Early uses. Renewed interest for silver" Burns 2000; 26: 117.

9. Lansdown ABG, Williams A.: "How safe is silver in wound care". J Wound Care 2004; 13(4): 131.

10. White RJ.: "An historical overview of the use of silver on wound management". Br J Nurs 2001; 10 (suppl): 3. 
11. Klasen HJ.: "A historical review of the use of silver in the treatment of burns. II. Renewed interest for silver". Burns 2000; 26: 131.

12. Lansdown ABG.: "Silver: It's antibacterial properties and mechanisms of action". J Wound Care 2002; 11(4): 125.

13. Dunn K, Edwrars-Jones V.: "The role of Acticoat with nanocrystaline silver in the management of burns". Burns 2004; (suppl 1): s1.

14. Ovington LG.: "Nanocrystaline silver: where the old and familiar meets a new frontier". Wounds 2001; 13(2) (suppl B: 5-10)

15. Li XZ, Nikaido H, Willimas KE: "Silver-resistant mutants of Escherichia coli display active efflix of Ag+ and are deficient in porins". J Bacteriology 1997; 179 (19): 6127.

16. Bhol KC, Schechter PJ.: "Topical nanocrystalline silver cream suppresses inflammatory cytokines and induces apoptosis of inflammatory cells in a murine model of allergic contact dermatitis". Br J Dermatol 2005; 152: 1235.

17. Voigt DV, Paul CN.: "The use of Acticoat as silver impregnated telfa dressings in a regional burn and wound care center: the clinicians view". Wounds 2001; (13): Suppl B: 11 .

18. Fong J, Wood F, Fowler B.A: "Silver coated dressing reduces the incidence of early burn wound cellulitis and associated costs of inpatient treatment: Comparative patient care audits". Burns 2005; (31): 562.

19. Fraser JF, Bodman J, Sturgess R, Faoagali J, Kimble RM.: "An in vitro study of the anti-microbial efficacy of a $1 \%$ silver sulphadiazine and $0,2 \%$ clorhexidine digluconate cream, $1 \%$ silver sulphadiazine cream and a silver coated dressing". Burns 2004; 30: 35.
20. Ulkur E, Oncul O, Karagoz H, Celikoz B, Cavuslu S.: "Comparison of Silver-Coated Dressing (Acticoat ${ }^{\circledR}$ ), Chlorhexidine Acetate $0.5 \%$ (Bactigras ${ }^{\circledR}$ ), and Silver Sulfadiazine 1\% (Silverdin $®$ ) for Topical Antibacterial Effect in Pseudomonas Aeruginosa-Contaminated, FullSkin Thickness Burn Wounds in Rats". J Burn Care Rehab 2005;26(5):430.

21. Tredget EE, Shankowsky HA, Groeneveld A, Burell R.: " A matched-pair randomized study evaluating the efficacy and safety of Acticoat silver-coated dressing for the treatment of burn wounds". J Burn Care Rehabil 1998; 19: 531.

22. Demling RH, DeSanti MDL.: "The rate of re-epithelization across mesehed skin grafts is increased with exposure to silver". Burns 2002; 28: 264.

23. Peters DA, Verchere C.: "Healing at home: Comparing cohorts of children with medium-sized burns treated as outpatients with in-hospital applied Acticoat to those children treated as inpatients with silver sulfadiazine". J Burn Care Res 2006; 27: 198.

24. Varas RP, O'Keeffe T, Namias N, Pizano LR, Quintana OD, Herrero Tellachea M, Rashid Q, Ward CG.: "A prospective, randomized trial of Acticoat versus silver sulfadiazine in the treatment of partial-thickness burns: Which method is less painful?". J Burn Care Rehab 2005;26(4):344.

25. Rustogi R, Mill J, Fraser JF, Kimble RM.: "The use of Acticoat in neonatal burns". Burns 2005; 31:878. 